\title{
Spatial heterogeneity and structure of bird populations: a case example with the eagle owl
}

\begin{abstract}
If individuals of the same population inhabit territories different in landscape structure and composition, experiencing habitat-specific demographic rates, then the landscape features become major determinants of the overall population characteristics. Few studies have tested how habitat-specific demography interacts with landscape heterogeneity to affect populations of territorial species. Here we report a 29-year study of an eagle owl (Bubo bubo) population in southern France. The aim of this study was to analyse how habitat heterogeneity could affect density and breeding performance. Mean productivity for the overall sample was $1.69 \pm 0.76$ fledglings per breeding pair and, after controlling for year effect, significant differences between territories were detected for productivity. A positive correlation was found between the percentage of pairs producing $50 \%$ of the annual fledged young (an index of the distribution of fecundity among nesting territories) and the mean reproductive outputs, that is the heterogeneous structure of the population determined that most/all pairs contributed to the annual production of young during good years, but the opposite during poor years (i.e. fewer pairs produced the majority of fledglings). Mean reproductive output was positively affected by percentage of open country and diet richness. Although other factors different to territory quality could affect demography parameters (e.g. quality of breeders), our results clearly showed a significant correlation between landscape features and population productivity.
\end{abstract}

V. Penteriani (\&) M. M. Delgado $\&$ M. Ferrer Department of Applied Biology,

Estacion Biologica de Donana,

C.S.I.C., Avda. de Marıa Luisa s/n.,

Pabellon del Peru, Apdo. 1056,

41013 Seville, Spain

E-mail: penteriani@ebd.csic.es

Tel.: +34-954-232340

M. Gallardo

Parc Naturel Regional du Luberon,

Apt, France
Keywords Spatial heterogeneity \& Territory quality \& Breeding performance $\&$ Coefficient of variation $\&$ Bird populations \& Eagle owl (Bubo bubo)

\section{Introduction}

Theoretical studies (e.g., Holt 1985; Morris 1988, 1994; Delibes et al. 2001) and their applications (e.g., Morris 1991; Ferrer and Donazar 1996; Both 1998) indicate that, in heterogeneous habitats, the spatial distribution of resources determines the different patterns of habitat selection and affects demographic parameters and dynamics of populations. If individuals of the same population inhabit territories different in landscape structure and composition, and experience habitat-specific demographic rates, then the landscape features and the distribution of individuals become major determinants of the overall population characteristics (Pulliam 1988). In particular, population characteristics of territorial and solitary breeding species are affected by the type of habitats surrounding a nest site and the heterogeneous distribution of resources within landscape. Both these factors can strongly influence density and breeding performance (Berg 1997; Rodenhouse et al. 1997, 1999), although we cannot ignore the contribution of age and individual quality to breeding performances. Moreover, McPeek et al. (2001) pointed out that the characteristics of a population can be determined by factors other than the individual intra- and inter-specific interactions: population processes can be affected by the quality of a breeding site, independently of population size. Space use patterns and social behaviour should be highly responsive to the abundance and distribution of food and cover, particularly in heterogeneous habitats (Ostfeld et al. 1985).

Variation in the suitability of territories probably exists to some degrees in most if not all natural animal populations (Rodenhouse et al. 1997; Delibes et al. 2001) and can be substantial. The importance of studying 
species living in landscapes where habitats are not equally productive is increased by the fact that territory with an overproduction of young may play an important role in source-sink systems (Ferrer and Donazar 1996; Pulliam 1988; Harrison and Taylor 1997), where emigration of individuals from territories of high quality maintains poorest ones (Blondel et al. 1991).

Although habitat heterogeneity in natural landscapes has often been emphasized (Wiens 1976; Turner 1989; Kotliar and Wiens 1990; Rodenhouse et al. 1997, 1999), few studies have tested how landscape structure affects animal population structure (e.g., Rosenzweig and Abramsky 1980; Ostfeld et al. 1985; Dobson and Oli 2001). Generally, the habitat heterogeneity was mainly correlated with species diversity and abundance (Bronmark 1985; Boecklen 1986; Thiollay 1990; Berg 1997), foraging efficiency (Roese et al. 1991), life-history variation in different populations (Blondel et al. 1993), population size (see review in Dobson and Oli 2001) and reproductive investment (Aron et al. 2001).

Because of the interactive nature of organisms and their environments, population studies need to elucidate the influences of the landscape on individual distribution and the demographic mechanisms of a population's response to those environmental influences (Kadmon 1993; Dobson and Oli 2001; Oli and Dobson 2001). For example, Ferrer and Donazar (1996), Rodenhouse et al. (1997, 1999) and Both (1998) have recently explored how the use of breeding territories or habitats that differ in suitability might influence reproductive performance. Indeed, whether and how animal populations are regulated remains one of the principal questions in ecology, which knowledge allows many important applications (Murdoch 1994; Rodenhouse et al. 1997; Dobson and Oli 2001; McPeek et al. 2001).

Mediterranean regions, characterized by checkerboard landscapes with a large variety of habitats due to land-use practices (Blondel et al. 1993; Naveh and Lieberman 1994; Blondel and Aronson 1999), provide an interesting case of study where mechanisms described above could be acting. For these reasons, we looked firstly for a possible effect of landscape heterogeneity in determining variations in breeding performance and density of a population of eagle owl (Bubo bubo) in southern France. For this purpose, we used information from a 29-year monitoring program of this population. Finally, conservation implications of population spatial heterogeneity are discussed.

\section{Materials and methods}

\section{Study area and species}

We conducted this study from 1971 to 1999 in a $1,200 \mathrm{~km}^{2}$ Mediterranean area of southern France (Luberon massif, Provence region). The area is in the Humid Mediterranean climatic zone (Donazar 1987), with elevation ranging from 160 to $700 \mathrm{~m}$. The lower and border area consists of the piedmont mountains and of the Durance river valley, characterized by intense human activities. The landscape comprises open areas (croplands, pastures and fallow lands) along the riverside, and Mediterranean forests dominated by Quercus ilex, Q. pubescens and Pinus halepensisand some matorral patches. Rocky areas are scattered through this sector, with several isolated small cliffs. The interior and higher elevation area comprises a mosaic structure of large rocky canyons, overhanging garrigues (mainly Q. coccifera, Thymus vulgaris and Rosmarinus officinalis) and Mediterranean forest.

The eagle owl is one of the largest predators of Mediterranean ecosystems. It is the largest Palearctic owl (1,500-3,500 g) and it is widely distributed across Europe, Asia and North Africa. It inhabits a large variety of habitats including boreal coniferous and mixed deciduous forests, Mediterranean scrub and steppes and rocky and sandy deserts. Its most characteristic hunting habitat is open country (Leditznig 1992, 1996; Mikkola 1994; Penteriani 1996). It is a sedentary and territorial owl, with a low reproductive rate (Penteriani 1996).

\section{Census of breeding pairs}

We collected a global sample of 35 eagle owl territories (see Appendix 1) using a combination of methods (Penteriani et al. 2001, 2002a,b), including: (a) searching rock areas that were mapped $(1: 25,000)$ and cliffs too small to be shown on topographic maps; (b) visiting cliffs in order to detect nests, pellets, feeding perches (October-February and May-July); (c) passive auditory surveys at sunrise and sunset, from October to February, when the vocal activity of adults was most intense (Penteriani 2002, 2003a); and (d) passive auditory surveys of calling young, from when chicks were about 40 days old until a month after they left the nest (MayJune in our study area). The listening sessions for calling young took place during the day (Penteriani et al. 2000) and the night (Mysterud and Dunker 1982). We used the nearest neighbour distances (NND) among breeding territories as an estimate of density. The density of the population remained stable during the overall 29-year period of the study (Penteriani et al. 2001).

Depending on the needs of both the information available for the whole data set and statistical treatments, several different sub-samples of the 35 territories were used in the different analyses (see Appendices 1, 2).

Nesting habitat quality

The analysis of landscape features determining the territory quality was based on 1,000 m-radius plots centred on 17 breeding territories for which it was possible to obtain aerial maps (Appendix 2; see also Appendix 1 to identify them in the yearly data set of reproductive 
output by territory). This scale was chosen because: (1) eagle owls prefer to nest near their favourite hunting grounds (Frey 1973; Olsson 1979; Donazar 1988; Leditznig 1992), and (2) breeding success is influenced by the distance from the nest to foraging areas (Leditznig 1996). We analysed the landscape with the IDRISI program (Geographical Information System, GIS), using a land cover layer and a digital elevation model (DEM) layer with a horizontal resolution of $50 \mathrm{~m}$ (for more information see Penteriani et al. 2001). We used an overall set of five variables to describe the nesting territory: two variables described land cover categories (percentage of open country and woodlands), two variables described horizontal heterogeneity (ecotone number-calculated along two orthogonal axes from the plot centre-and Shannon diversity index), and minimum distance of the nest from the nearest patch of open country. The above-mentioned variables have been proved to be the most important one in the description of the eagle owl nest site structure in our study area (Penteriani et al. 2001).

\section{Diet characteristics}

We analysed diet by repeated visits to 17 territories during the last 5 years of the study period (see Appendix 2 ), and collected prey remains and pellets. Each year, we visited the entire sample of territories three times: just before egg-laying, immediately after fledging and during autumn. Additional direct observations at sunset and sunrise were also included. The combination of different methods to determine diet may yield more accurate estimates of the diet features than using just one method (Simmons et al. 1991; Marchesi et al. 2002). Prey remains and pellets were identified by macroscopic comparison with reference collections. We pooled pellets from individual visits into a single sample for analysis. To avoid duplication of prey i.e., in remains and pellets, items found in pellets were used only if they had not been found as remains during the same visit (Penteriani 1997).

For the analyses, we used the two parameters of the eagle owl diet that showed to be related with the breeding performance of our population (for more details on diet features see Penteriani et al. 2002a), which can be considered as good indicators of the quality and suitability of habitat and food resources:

1. Richness (number of identified prey species in the diet; Magurran 1988)

2. Diversity, measured by the Shannon index (Magurran 1988)

$$
\mathrm{H}^{0} 1 / 4-\mathrm{p}_{\mathrm{i}} \ln \mathrm{p}_{\mathrm{i}}
$$

where $\mathrm{p}_{\mathrm{i}}$ is the proportional abundance of the ith species $=\mathrm{n}_{\mathrm{i}} / \mathrm{N}_{\text {(total) }}$. Values of diet richness major or equal of mean population diet richness were considered as an indicator of a high-richness diet.

\section{Breeding performances}

Each nest was visited several times, but mainly during two periods: (1) the pre-laying period (from October to mid-February) to check for occupancy, and (2) the nestling (starting when chicks were about 2-3 weeks old) and the fledgling periods (until August). Two measures of productivity were used, the number and the coefficient of variation $(\mathrm{CV})$ of young fledged per breeding pair. Because it was not possible to check the productivity for each territory each year, we used mean values of fledged young per territory to avoid pseudoreplications when necessary. Although other population parameters could describe breeding performances (e.g., clutch size, fledging survival rate and dispersal, breeding population recruitment), the number of fledged young per territory per year represents one of the crucial descriptors of the population productivity (Penteriani et al. 2002a,b), being considered as an index of the quality of a nesting territory (Penteriani et al. 2002a; Sergio and Newton 2003). Following the terminology proposed by Steenhof (1987), a breeding pair was one that laid eggs.

Breeding performances of eagle owls were analysed over a period of 29 years, except when exploring the overall population fecundity and relationships between mean productive outputs, CV and NND, for which we used only the 18 years during which we were able to obtain data for at least ten territories each year (see Appendix 1). As for the CV patterns between territories, we assumed that a dependence of the population on habitat heterogeneity should generate, during poor years, higher fluctuations of this parameter (i.e. heterogeneous distribution of fertility within the population) due to lower breeding performance in the territories of lowest quality.

Information on breeder longevity and pair bond duration of our population was not available, because of the impossibility of marking individuals. However, eagle owl survival in the field seems to be approximately 1520 years (Olsson 1979) and mate fidelity is high (Penteriani 1996).

\section{Statistical analyses}

To analyse the population heterogeneity we used several procedures. Firstly, to test for the effect of territory quality on the overall population fecundity, we eliminated the year effect on productivity (Penteriani et al. $2003 b)$. Owing to the existing annual variations, we controlled for year effects by subtracting annual means from the row data. For the number of fledglings, negative values indicate a poorer breeding performance than average, whereas positive values indicate a better one. Relative productivity was analysed by a univariate ANOVA, with the nesting territory as a random factor to correct for pseudoreplication.

Then, we tested a new variable allowing us to detect intrinsic variability of populations by the evaluation of 
the distribution of fecundity among nesting territories. Our assumption was that a heterogeneous structure of the population, characterised by high- and low-quality sites, determines that most pairs of a population contribute homogeneously to the annual production of young during good years, but the opposite during poor years (i.e. few pairs will produce the majority of fledglings). To do this, we considered the percentage of breeding pairs producing at least $50 \%$ of the annual fledged young. We calculated this parameter by summing the number of fledged young (starting from the pairs with higher productivity) necessary to attain $50 \%$ of the annual young production (hereafter, \% of contributing pairs). This parameter has the advantage of (a) giving accurate information of the degree of heterogeneity of a population by the portion of the breeding population main contributing to the annual production of young (not detectable by simply using the percentage of successful pairs, from which no information is available on the distribution of fecundity), and (b) being independent from the low clutch-size of several bird species, which could affect the ratio of the coefficient of variation (i.e. standard deviation of the productivity/ mean productivity).

Finally, to detect whether and how the eight previously presented parameters of landscape structure, diet and density could explain differences in mean reproductive output and its annual variance within the population, we ran two forward stepwise multiple regression models using (a) mean number of fledglings and CV as dependent variables, and (b) the 17 territories for which all the eight parameters were available.

When data were not normally distributed, they were $\log _{e}$ and square-root transformed (Sokal and Rohlf 1995). When multiple comparisons were carried out on a set of values, the sequential Bonferroni correction was used to adjust the significance level (Rice 1989). All means are given with $\pm S D$, all tests are two-tailed, and statistical significance was set at $\mathrm{P}<0.05$. Software packages were STATISTICA and SPSS 10.0.

\section{Results}

During the study period, mean productivity for the overall sample was $1.69 \pm 0.76$ fledgling per breeding pair $(n=279$, range $=1-3)$. After controlling for year effect, significant differences among territories were detected for productivity $(\mathrm{F}=2.80, \mathrm{df}=17,245, \mathrm{P}=0.0001)$. A positive correlation was detected between the percent of contributing pairs and the mean reproductive output for the population $(\mathrm{r}=0.712, \mathrm{P}<0.001$; see also Fig. 1$)$. When considering the mean percent of contributing pairs as a threshold to separate good from poor years, more pairs showed a significant contribution $(t=-5.41$, $\mathrm{P}=0.0001)$ to the production of young during good years $(40.6 \pm 1.4 \%)$ than poor years $(34.7 \pm 3.9 \%)$.

The multiple regression models testing the influence of landscape structure, diet and density on mean

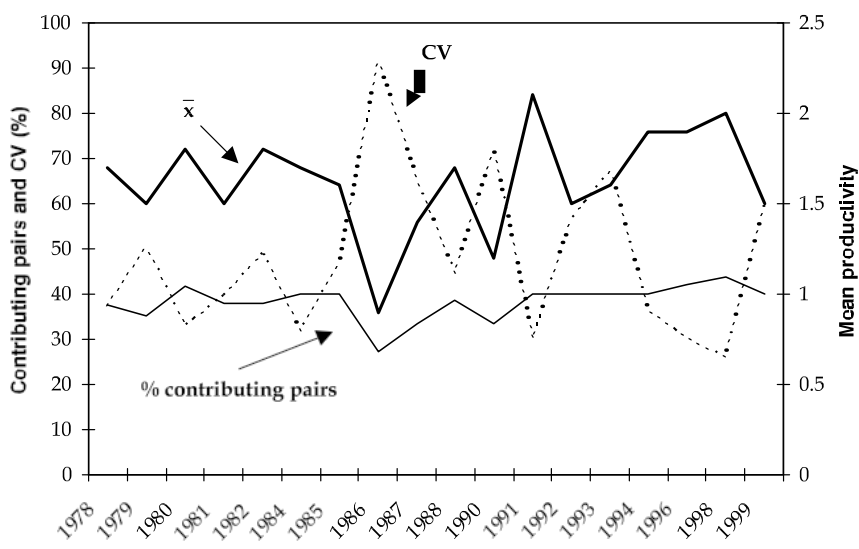

Fig. 1 Patterns of mean productivity (bold line), coefficient of variation (light line) and percent of contributing pair (see text for description; solid line) of the eagle owl territories during a period of 29 years. In years with high reproductive outputs, differences in the fecundity distribution between territories were smaller than in poor years (as showed by the pattern of the coefficient of variation), when fewer pairs contributed to the whole production of fledglings

reproductive output and CV showed that (Table 1) (1) percentage of open country within the nesting territory and diet richness showed a positive correlation with number of fledglings; and (2) CV was negatively affected by percentage of open country and positively related to the NNDs of the population. In this last model, diet richness also entered as an explanatory variable, but its positive correlation was not significant $(b=0.36$, $\mathrm{t}=1.15, \mathrm{P}=0.27)$. Also, NNDs was significantly shorter in the territories with higher richness in $\operatorname{diet}(\mathrm{F}=29.70$, $\mathrm{df}=1,15, \mathrm{P}<0.001)$. These results evidenced that more fecund territories, also characterised by high richness in diet, were located in areas of higher breeding density.

\section{Discussion}

The detected differences in productivity among territories, the patterns of the percent of contributing pairs, as well as the variations in the population $\mathrm{CV}$ indicated that, in years with an overall high reproductive output (reflecting good years), differences in fecundity between territories were small, whereas in years with low mean reproductive output (i.e. poor years), differences between territories became substantial. This result evidences a heterogeneous structure within the population, characterised by territories of different quality, the lowest quality territories showing higher annual variance in productivity.

Although animal populations are frequently considered as a unique entity, characterized by homogeneous responses to stresses, alterations or landscape features, they might work as systems that are more complex and be composed of sub-units characterized by high intrinsic variance (Ferrer and Donazar 1996). In the studied population, we identified the high percentage of open country as the main landscape element determining territory quality. This landscape feature may account for the higher 
Table 1 Parameters of landscape structure, diet and density (see Materials and methods for details) affecting eagle owl reproductive success. Model summary and coefficients of the two forward stepwise multiple regression models that we performed using mean reproductive output and CV as dependent variables are shown $(\mathrm{n}=17)$

\begin{tabular}{lcrr}
\hline & $\mathrm{b}$ & $\mathrm{t}$ & \\
\hline Dependent variable: number of fledglings $\left(\mathrm{R}^{2}=0.57\right)$ & & 3.58 & $\mathrm{P}$ \\
Percentage of open country & 0.63 & 2.34 & 0.01 \\
Diet richness & 0.41 & & 0.03 \\
Dependent variable: coefficient of variation of productivity $\left(\mathrm{R}^{2}=0.54\right)$ & -0.55 & -2.93 & 0.01 \\
Percentage of open country & 0.74 & 2.34 & 0.04 \\
Nearest neighbour distance & & & \\
\hline
\end{tabular}

diet richness of the individuals occupying best territories, which could contribute to their higher number of fledglings and inter-annual stability in productivity. This characterisation represents an important finding because, as pointed out by Pulliam (2000), little is known about the distribution and determinants of territory suitability because the environmental causes of site heterogeneity are seldom measured. Moreover, our results support the hypothesis that among-territory variation of breeding traits also represents a response to variation in the food supply, as suggested by Lack (1966), Klomp (1970), Drent and Daan (1980), Ricklefs (1983) and Martin (1987). Other raptor studies have demonstrated the importance of diet features in determining reproduction (Korpimaki 1984, 1992; Potapov 1997; Steenhof et al. 1997, 1999).

Although factors other than territory quality could affect demography parameters (e.g., individual quality of breeders, higher-quality individuals occupying best territories), the results we obtained clearly showed a significant correlation between landscape features and population productivity. As previously observed, it is difficult to clearly separate the effect of the individual from that of the habitat quality on breeding performance (Ferrer and Donazar 1996; Rodenhouse et al. 1999; Kruger and Lindstrom 2001). Traits of individuals (e.g., territory fidelity, age and breeding experience) could enhance environmentally caused differences in suitability (Rodenhouse et al. 1997), and occur at all population densities. Actually, both these factors may operate at the same time and may not be mutually exclusive, and the interactions between habitat and productivity complicate any predictions of the effects of individual quality. In our specific case, the duration of the study is longer than the life spans of most eagle owl individuals (Penteriani 1996), thus habitat heterogeneity may undoubtedly contribute to explain the trends we observed in productivity. Other works similarly demonstrated a relationship between the average reproduction and the quality of the territory, showing habitatspecific dependence of animal demographic parameters (Weatherhead and Robertson 1977; Korpimaki 1988; Andren 1990; Virkkala 1990; Wauters and Dhondt 1990; Goodburn 1991; Ens et al. 1992; Komdeur 1992; Strauss van and Gluck 1995; Wauters and Lens 1995; Ferrer and Donazar 1996; Bollmann et al. 1997).

The preference for open patches showed by eagle owls is consistent with Leditznig (1996), who showed that the distance between the nest cliff and open areas seems to be related to breeding success, and the more forested the home range, the lower the reproductive success of single pairs, primarily because of reduced prey abundance and availability. These results are also consistent with earlier analysis of the nesting habitat at the landscape level, suggesting that eagle owls require nesting sites in a heterogeneous landscape with a preference for open patches (Blondel and Badan 1976; Penteriani et al. 2001).

The frequently claimed effects of density-dependence did not affect productivity parameters in the studied population. In the sample we studied, CV was positively correlated with NNDs (lower in best territories with higher diet richness). That is, the best territories, more stable in the annual variance of breeding performance, supported a higher density. This result seems inconsistent with the hypothesis that, in suboptimal habitats, the density can be higher than in optimal ones (Fretwell and Lucas 1970; Virkkala 1990), and that higher densities may depress productive output because of increasing interspecific interaction (interference hypothesis, e.g., Lack 1966; Fretwell and Lucas 1970; Dhondt and Schillemans 1983). For this reason, we need to use the term density-dependence carefully when relating demographic parameters to population size and/or growth, without referring to the effective density in the territory. Numerical growth of populations does not necessarily mean an increasing density in terms of individuals and/or breeding pairs in a given area. Rodenhouse et al. (1997, 1999) expressed the possibility that the demographic parameters may sometimes be independent of density for site-dependent species (such as eagle owl) in which individual fitness depends on exclusive use of a site (e.g., territory). This independence operates when breeding pairs living in spatially heterogeneous environments preemptively use sites that differ in suitability for reproduction and/or survival, as well as when changes are produced by stochastic events or human disturbance.

Finally, such a heterogeneity detected in the structure of our eagle owl population may highlight several important consequences in terms of genetics and conservation of bird (animal) populations. Actually, in situations where several (best quality) territories regularly produce the majority of the young present in the population, the amount of genetic contribution and variability from this part of the population to the 
overall population will be greater than the contribution from low quality territories. Moreover (1) in times of open country losses in Mediterranean landscapes due to a decrease in livestock grazing pressure combined with abandonment of agricultural uplands (Naveh and Lieberman 1994), the desertion of optimal territories can have important consequences for the whole population (Ferrer and Donazar 1996; Sutherland 1996; Kokko and Sutherland 1998); (2) it is important to locate high- and low-quality breeding sites to both (a) preserve the annual production of young of the best territories and (b) establish the factors determining the low-quality of the poorest territories to try to improve their quality; and (3) the possibility of detecting and predicting the mechanisms acting on animal populations gives support to conservation efforts by identifying the factors and conditions that determine population parameters (Rodenhouse et al. 1999).

Acknowledgments D. Becker, M. Forero, O. Kruger, M. Monkkonen, N. L. Rodenhouse, T. Sota and three anonymous referees made a useful critique of the first draft of the manuscript. We thank P. Roche for helping with the IDRISI program, H. Magnin, C. Horisberger and P. Horisberger and O. Maubec for the logistic help during the fieldwork. During the study, V. P. received a research grant from the Regional Park of Luberon (France) and a post-doctoral grant from the Estacion Biologica de Donana (Consejo Superior de Investigaciones Cientıficas, Spain).

\section{Appendix 1}

Territory-specific yearly data of reproductive output (i.e. number of fledglings) of the French population of eagle owls during the 29 years of the study. The years 1973 and 1974 are absent because during this period it was impossible to collect data in the field (-, missing data). Mean number of fledglings, coefficient of reproduction (CV) and percentage of contributing pairs (\%) per year was only presented for the 18 years shown in Fig. 1 and during which we were able to obtain data for at least ten territories each year (see details in Materials and methods)

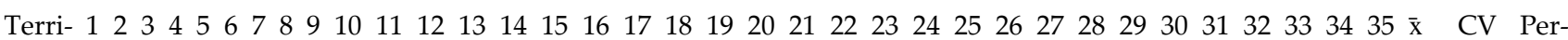
tories

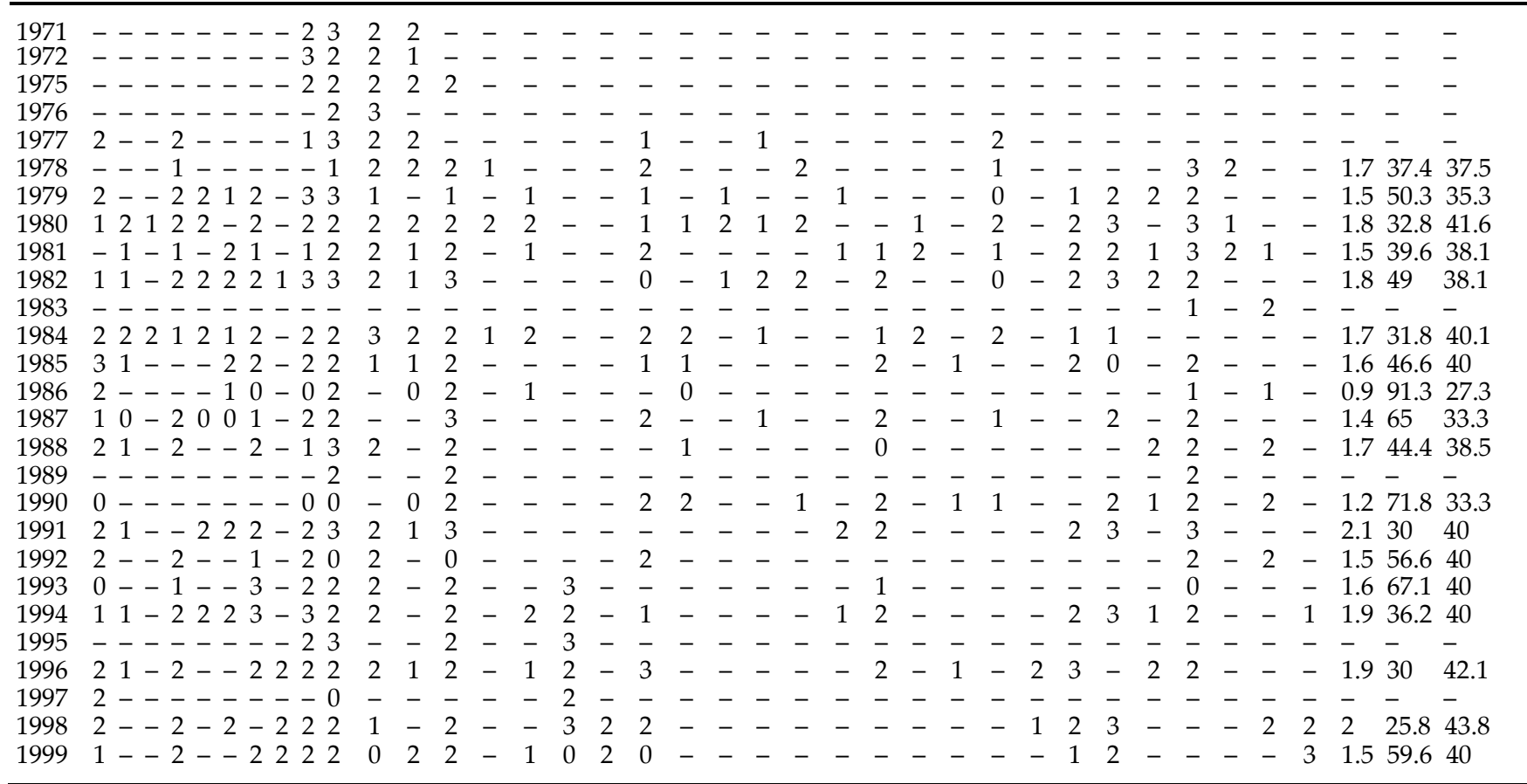




\section{Appendix 2}

Raw data for the eight variables of landscape structure, diet and density (see Materials and methods for details) that we used to explain differences in mean reproductive output and its annual variance within the population. The results of the two forward stepwise multiple regression models that we performed using mean reproductive output and CV as dependent variables are summarised in Table 1

\begin{tabular}{lllllllllllllllllll}
\hline Territories $^{\mathrm{a}}$ & 1 & 2 & 4 & 6 & 7 & 9 & 10 & 11 & 12 & 13 & 16 & 18 & 19 & 29 & 30 & 32 & 34 \\
\hline Percentage of open country & 19.4 & 29.4 & 30.3 & 26.1 & 29.6 & 22.3 & 60.5 & 38.4 & 49.5 & 74.5 & 43.1 & 31.5 & 12.5 & 55.1 & 53.1 & 45.1 & 26.9 \\
Percentage of woodland & 38.2 & 37.2 & 41.8 & 59.3 & 58.5 & 68.1 & 20.7 & 50.2 & 28.7 & 9.3 & 22.8 & 27.1 & 49.6 & 10.6 & 12.8 & 22.8 & 31.6 \\
Number of ecotones & 11.5 & 14.9 & 15.1 & 14.5 & 12.3 & 13.5 & 15.4 & 14.1 & 11.2 & 11.9 & 13.5 & 13.1 & 12.8 & 13.5 & 13.5 & 13.5 & 11.9 \\
Shannon diversity index & 1.7 & 1.9 & 1.9 & 1.6 & 1.6 & 1.4 & 1.9 & 1.8 & 2 & 1.8 & 2 & 2 & 1.6 & 2 & 2 & 2 & 1.8 \\
NND (m) & 800 & 780 & 1200 & 670 & 1,200 & 1,000 & 760 & 760 & 2,000 & 2,550 & 900 & 3,500 & 3,600 & 1,000 & 1,500 & 1,600 & 2,500 \\
Diet richness & 70 & 70 & 30 & 68 & 69 & 70 & 70 & 70 & 30 & 31 & 68 & 32 & 32 & 65 & 69 & 69 & 32 \\
Diet diversity & 2.3 & 2.3 & 1.9 & 2.3 & 2.3 & 2.2 & 2.2 & 2.1 & 1.9 & 1.9 & 2.1 & 1.9 & 1.9 & 2.3 & 2.3 & 2.3 & 1.9 \\
Distance (m) from the nearest patch & 40.7 & 27.5 & 0.0 & 0.0 & 0.0 & 159.8 & 0.0 & 27.5 & 0.0 & 0.0 & 27.5 & 55.0 & 27.5 & 22.5 & 27.5 & 12.7 & 87.0 \\
of open country & & & & & & & & & & & & & &
\end{tabular}

${ }^{a}$ The numbers identifying each territory correspond to the ones in Appendix 1

\section{References}

Andren H (1990) Despotic distribution, unequal reproductive success, and population regulation in the Jay Garrulus glandarius L. Ecology 71:1796-1803

Aron S, Keller L, Passera L (2001) Role of resource availability on sex, caste and reproductive allocation ratios in the Argentine ant Linepithema humile. J Anim Ecol 70:831-839

Berg A (1997) Diversity and abundance of birds in relation to forest fragmentation, habitat quality and heterogeneity. Bird Study 44:355-366

Blondel J, Aronson J (1999) Biology and wildlife of the Mediterranean region. Oxford University Press, Oxford

Blondel J, Badan O (1976) La biologie du Hibou grand-duc en Provence. Nos Oiseaux 33:189-219

Blondel J, Perret P, Maistre M, Dias PC (1991) Do harlequin Mediterranean environments function as source sink for Blue Tits (Parus caeruleus)? Land Ecol 6:213-219

Blondel J, Dias PC, Maistre M, Perret P (1993) Habitat heterogeneity and life-history variation of Mediterranean Blue Tits (Parus caeruleus). Auk 110:511-520

Boecklen WJ (1986) Effects of habitat heterogeneity on the speciesarea relationship of forest birds. J Biogeogr 13:59-68

Bollmann K, Reyer HU, Brodmann PA (1997) Territory quality and reproductive success: can water pipits Anthus spinoletta assess the relationship reliably? Ardea 85:83-98

Both C (1998) Density dependence of clutch size: habitat heterogeneity or individual adjustment? J Anim Ecol 67:659-666

Bronmark C (1985) Freshwater snail diversity: effects of pond area, habitat heterogeneity and isolation. Oecologia 67:127-131

Delibes M, Gaona P, Ferreras P (2001) Effects of an attractive sink leading into maladaptive habitat selection. Am Nat 3:277-285

Dhondt AA, Schillemans J(1983) Reproductive success of the great tit in relation to its territorial status. Anim Behav 31:902-912

Dobson FS, Oli MK (2001) The demographic basis of population regulation in Columbian Ground Squirrels. Am Nat 158:236-247

Donazar JA (1987) Geographic variations in the diet of the Eagle Owls in Western Mediterranean Europe. In: Nero RW, Clark RJ, Knapton RJ, Hamre RH (eds) Biology and conservation of northern forest owl. General Technical Report RM-142. USDA, Fort Collins, pp 220-224

Donazar JA (1988) Seleccion del habitat de nidificacion por el Buho real (Bubo bubo) en Navarra. Ardeola 35:233-245

Drent RH, Daan S (1980) The prudent parent: energetic adjustments in avian breeding. Ardea 68:225-252

Ens BJ, Kersten M, Brenninkmeijer A, Hulscher JB (1992) Territory quality, parental effort, and reproductive success of
Oystercatchers (Haematopus ostralegus). J Anim Ecol 61:703716

Ferrer M, Donazar JA (1996) Density-dependent fecundity by habitat heterogeneity in an increasing population of Spanish Imperial Eagles. Ecology 77:69-74

Fretwell SD, Lucas JHJ (1970) On territorial behaviour and other factors influencing habitat distribution in birds. Acta Biotheor 19:16-36

Frey H (1973) Zur Okologie niederosterreichischer Uhupopulationen. Egretta 16:1-68

Goodburn SF (1991) Territory quality or bird quality? Factors determining breeding success in the Magpie Pica pica. Ibis 133:85-90

Harrison S, Taylor AD (1997) Empirical evidence for metapopulation dynamics. In: Hanski A, Gilpin ME (eds) Metapopulation biology. Academic, San Diego, pp 27-42

Holt RD (1985) Population dynamics in two-patch environments: some anomalous consequences of an optimal habitat distribution. Theor Popul Biol 28:181-208

Kadmon R (1993) Population dynamic consequences of habitat heterogeneity: an experimental study. Ecology 74:816-825

Klomp H (1970) The determination of clutch size in birds: a review. Ardea 58:1-124

Kokko H, Sutherland WJ (1998) Optimal floating and queuing strategies: consequences for density dependence and habitat loss. Am Nat 152:354-366

Komdeur J (1992) Importance of habitat saturation and territory quality for evolution of cooperative breeding in the Seychelles warbler. Nature 358:493-495

Korpimaki E (1984) Population dynamics of birds of prey in relation to fluctuations in small mammal populations in western Finland. Ann Zool Fenn 21:287-293

Korpimaki E (1988) Effects of territory quality on occupancy, breeding performance and breeding dispersal in Tengmalm's Owl. J Anim Ecol 57:97-108

Korpimaki E (1992) Diet composition, prey choice, and breeding success of long-eared owls: effects of multiannual fluctuations in food abundance. Can J Zool 70:2373-2381

Kotliar NB, Wiens JA (1990) Multiple scales of patchiness and patch structure: a hierarchical framework for the study of heterogeneity. Oikos 59:253-260

Kruger O, Lindstrom J (2001) Habitat heterogeneity affects population growth in goshawk Accipiter gentilis. J Anim Ecol 70:173-181

Lack D (1966) Population studies of birds. Clarendon Press, Oxford

Leditznig C (1992) Telemetric study in the Eagle Owl (Bubo bubo) in the foreland of the Alps in Lower Austria - methods and first results. Egretta 35:69-72 
Leditznig C (1996) Habitatwahl des Uhus (Bubo bubo) im Sudwesten Niederosterreichs und in den donaunahen Gebieten des Muhlviertels auf Basis radiotelemetrischer Untersuchungen. Abh Zool-Bot Ges Osterreich 29:47-68

Magurran AE (1988) Ecological diversity and its measurement. Croom Helm, London

Marchesi L, Pedrini P, Sergio F (2002) Biases associated with diet study methods in the eagle owl. J Raptor Res 36:11-16

Martin TE (1987) Food as limit on breeding birds: a life-history perspective. Annu Rev Ecol Syst 18:453-487

McPeek MA, Rodenhouse NL, Holmes RT, Sherry TW (2001) A general model of site-dependent population regulation: population-level regulation without individual-level interactions. Oikos 94:417-424

Mikkola H (1994) Eagle owl. In: Tucker GM, Heath MF (eds) Birds in Europe: their conservation status. Birdlife conservation series, vol. 3. Cambridge University Press, Cambridge, pp 326327

Morris DW (1988) Habitat-dependent population regulation and community structure. Evol Ecol 2:253-269

Morris DW (1991) Fitness and patch selection in white-footed mice. Am Nat 138:702-716

Morris DW (1994) Habitat matching: alternatives and implications to populations and communities. Evol Ecol 8:387-406

Murdoch WW (1994) Population regulation in theory and practice. Ecology 75:271-287

Mysterud I, Dunker H (1982) Food and nesting ecology of the Eagle Owl, Bubo bubo (L.), in four neighbouring territories in Southern Norway. Viltrevy 12:71-113

Naveh Z, Lieberman A (1994) Landscape ecology. Theory and application. Springer, Berlin Heidelberg New York

Oli MK, Dobson FS (2001) Population cycles in small mammals: the a hypothesis. J Mammal 82:573-581

Olsson V (1979) Studies of a population of eagle owls, Bubo bubo (L.), in southwest Sweden. Viltrevy 11:1-99

Ostfeld RS, Lidicker WZ Jr, Heske EJ (1985) The relationship between habitat heterogeneity, space use, and demography in a population of California voles. Oikos 45:433-442

Penteriani V (1996) The eagle owl (in Italian). Calderini Edagricole, Bologna

Penteriani V (1997) Long-term study of a goshawk breeding population on a Mediterranean mountain (Abruzzi Apennines, Central Italy): density, breeding performances and diet. J Raptor Res 31:308-312

Penteriani V (2002) Variation in the function of the eagle owl vocal behaviour: territorial defence and intra-pair communication? Ethol Ecol Evol 14:275-281

Penteriani V (2003a) Breeding density affects the honesty of bird vocal displays as possible indicators of male/territory quality. Ibis 145:E127-E135

Penteriani V (2003b) Simultaneous effects of age and territory quality on fecundity in Bonelli's Eagle Hieraaetus fasciatus. Ibis 145:E77-E82

Penteriani V, Gallardo M, Cazassus H (2000) Diurnal vocal activity of young eagle owls and its implications in detecting occupied nests. J Raptor Res 34:232-235

Penteriani V, Gallardo M, Roche P, Cazassus H (2001) Effects of landscape spatial structure and composition on the settlement of the Eagle Owl Bubo bubo in a Mediterranean habitat. Ardea 89:331-340

Penteriani V, Gallardo M, Roche P (2002a) Landscape structure and food supply affect eagle owl Bubo bubo density and breeding performance: a case of intra-population heterogeneity. J Zool 257:365-372

Penteriani V, Faivre B, Mazuc J, Cezilly F (2002b) Pre-laying vocal activity as a signal of male and nest stand quality in goshawks. Ethol Ecol Evol 14:9-17
Potapov ER (1997) What determines the population density and reproductive success of rough-legged buzzards, Buteo lagopus, in the Siberian tundra? Oikos 78:362-378

Pulliam HR (1988) Sources, sinks, and population regulation. Am Nat 132:652-661

Pulliam HR (2000) On the relationship between niche and distribution. Ecol Lett 3:349-361

Rice WR (1989) Analyzing tables of statistical tests. Evolution 43:223-225

Ricklefs RE (1983) Avian demography. Curr Ornithol 1:1-32

Rodenhouse NL, Sherry TW, Holmes RT (1997) Site-dependent regulation of population size: a new synthesis. Ecology 78:2025-2042

Rodenhouse NL, Sherry TW, Holmes RT (1999) Multiple mechanisms of population regulation: contributions of site dependence, crowding, and age structure. In: Proceedings of international ornithological congress, vol 22, pp 2939-2952

Roese JH, Risenhoover KL, Folse LJ (1991) Habitat heterogeneity and foraging efficiency: an individual-based model. Ecol Model 57:133-143

Rosenzweig ML, Abramsky Z(1980) Microtine cycles: the role of habitat heterogeneity. Oikos 34:141-146

Sergio F, Newton I (2003) Occupancy as a measure of territory quality. J Anim Ecol 72:857-865

Simmons RE, Avery DM, Avery G (1991) Biases in diets determined from pellets and remains: correction factors for a mammal and bird-eating raptor. J Raptor Res 25:63-67

Sokal RR, Rohlf FJ (1995) Biometry, the principles and practice of statistics in biological research. Freeman, New York

Steenhof K (1987) Assessing raptor reproductive success and productivity. In: Pendleton G, Millsap BA, Cline KW, Bird DM (eds) Raptor management techniques manual. National Wildlife Federation, Washington, pp 157-170

Steenhof K, Kochert MN, McDonald TL (1997) Interactive effects of prey and weather on golden eagle reproduction. J Anim Ecol 66:350-362

Steenhof K, Kochert MN, Carpenter LB, Lehman RN (1999) Long-term prairie falcon population changes in relation to prey abundance, weather, land uses, and habitat conditions. Condor 101:28-41

Strauss von MJ, Gluck E (1995) Einfluß unterschiedlicher Habitatqualitat auf Brutphanologie und Reproduktionserfolg bei Blaumeisen (Parus caeruleus). Vogelwarte 38:10-23

Sutherland WJ (1996) From individual behaviour to population ecology. Oxford University Press, Oxford

Thiollay JM (1990) Comparative diversity of temperate and tropical forest bird communities: the influence of habitat heterogeneity. Acta Ecol 11: 887-911

Turner MG (1989) Landscape ecology: the effect of pattern on processes. Annu Rev Ecol Syst 20:171-197

Virkkala R (1990) Ecology of the Siberian Tit Parus cinctus in relation to habitat quality: effects of forest management. Ornis Scand 21:139-146

Wauters LA, Dhondt AA (1990) Red squirrel (Sciurus vulgaris Linnaeus, 1758) population dynamics in different habitats. Z Saugetierkd 55:161-175

Wauters LA, Lens L (1995) Effects of food availability and density on red squirrel (Sciurus vulgaris) reproduction. Ecology 76:2460-2469

Weatherhead PJ, Robertson RJ (1977) Harem size, territory quality, and reproductive success in the redwinged blackbird (Agelaius phoeniceus). Can J Zool 55:1261-1267

Wiens JA (1976) Population responses to patchy environments. Annu Rev Ecol Syst 7:81-120 